\title{
The potential for sound sensitivity in cephalopods
}

\author{
T. Aran Mooney ${ }^{1,2}$, Roger Hanlon ${ }^{2}$, Peter T. Madsen ${ }^{1,4}$, Jakob Christensen-Dalsgaard ${ }^{3}$, Darlene R. \\ Ketten $^{1,5}$ and Paul E. Nachtigall ${ }^{6}$ \\ ${ }^{1}$ Biology Department, Woods Hole Oceanographic Institution, Woods Hole, MA, USA, \\ amooney@whoi.edu (corresponding author) \\ ${ }^{2}$ Marine Biological Laboratory, Woods Hole, MA, USA \\ ${ }^{3}$ Institute of Biology, University of Southern Denmark, 5230 Odense M, Denmark, \\ ${ }^{4}$ Department of Biological Sciences, University of Aarhus, 8000 Aarhus G, Denmark \\ ${ }^{5}$ Department of Otology and Laryngology, Harvard Medical School, Boston, MA, USA \\ ${ }^{5}$ Hawaii Institute of Marine Biology, University of Hawaii, Kaneohe, HI, USA
}

\section{Introduction}

Hearing is a primary sense in many marine animals and we now have a reasonable understanding of what stimuli generate clear responses, the frequency range of sensitivity, expected threshold values and mechanisms of sound detection for several species of marine mammals and fishes (Fay 1988; Au et al. 2000). For marine invertebrates, our knowledge of hearing capabilities is relatively poor and a definition or even certainty of sound detection is not agreed upon (Webster et al. 1992) despite their magnitude of biomass and often central role in ocean ecosystems.

Cephalopods (squid, cuttlefish, octopods and nautilus) are particularly interesting subjects for invertebrate sound detection investigations for several reasons. Ecologically, they occupy many of the same niches as sound-sensitive fish (Budelmann 1994) and may benefit from sound perception and use for the same reasons, such as to detect predators, navigate, or locate conspecifics. Squid, for example, are often 
the prey of loud, echolocating marine mammals (Clarke 1996), and may therefore be expected to have evolved hearing to avoid predators. Anatomically, squid have complex statocysts that are considered to serve primarily as vestibular and acceleration detectors (Nixon and Young 2003). However, statocysts may also be analogs for fish otolithic organs, detecting acoustic stimuli (Budelmann 1992). Previous studies have debated the subject of squid hearing and recently there has been a revival of research on the subject. Here, we briefly review what is known about squid sound detection, revisit hearing definitions, discuss potential squid susceptibility to anthropogenic noise and suggest potential future research directions to examine squid acoustic sensitivity.

\section{The Sensitivity of Squid to Acoustic Stimuli}

Early anecdotal reports suggested that cephalopods might detect sounds because squid were attracted to $600 \mathrm{~Hz}$ tones and cuttlefish (Sepia officinalis) elicited startle responses to $180 \mathrm{~Hz}$ stimuli (Dijkgraaf 1963; Maniwa 1976). Norris and Møhl (1983) later postulated that squid might be debilitated by the acoustic intensity of foraging odontocete (toothed whale and dolphin) echolocation clicks. This hypothesis led Moynihan (1985) to suggest that squid might, in turn, be deaf to acoustic stimuli to avoid this "stunning." However, anatomical evidence of squid statocysts indicate that the organ acts as an accelerometer (Budelmann 1976) potentially used for acoustic detection (Budelmann 1992). Behavioral conditioning experiments later confirmed that squid (Loligo vulgaris), octopus (Octopus vulgaris) and S. officinalis can detect acceleration stimuli from 1-100 Hz, presumably by using the statocyst organ as an accelerometer detecting the body movements of the squid in the sound field (Packard et al. 1990). This and a follow-up study (Kaifu et al. 2008) showed that cephalopods can detect the low-frequency particle motion component of a sound field, but the question whether cephalopods are also sensitive to higher-frequencies and sound pressures still remained. Recent laboratory experiments have demonstrated that squid do not exhibit anti-predator responses in the presence of odontocete echolocation clicks (Wilson et al. 2007) indicating that they cannot detect the ultrasonic pressure component of a sound field. However, recently, Hu et al. (2009) suggested that squid (Sepiotheutis lessoniana) can detect sound pressure stimuli using their 
statocyst organ. Unfortunately, these data had several methodological issues including no calibrations of particle motion and placing squid at the water's surface where discrepancies between sound pressure and particle motion are greatest. Thus cephalopods seem to be sensitive to the low frequency particle motion component of the sound field and not pressure. Yet it appears necessary to discuss whether such a sensitivity can be understood as hearing.

\section{Defining “Hearing” (For Squid and Other Maine Organisms)}

There is no inherent reason why the definition of "hearing" should be taxon specific. It arguably should be based on the ability to detect acoustic stimuli per se and on the ability to analyze acoustic properties of a stimulus. Thus, this should not be a discussion about whether hearing fits squid perceptual mechanisms but whether squid perceptual abilities fit the broader scope of "hearing."

Yost (1994) defines hearing broadly as sensitivity to sounds in the environment and encompassing coding, processing, integration and response of sound. An alternative definition suggests that hearing is the auditory detection of sound (Webster et al. 1992). Both definitions are similarly open-ended, probably intentionally so. Both also presume a definition of sound which is a well-defined hydrodynamic wave that propagates in an elastic medium by pressure and particle motion oscillations (Kalmijn 1988). In the marine environment, an air cavity or at least some compressible tissue in the vicinity of the fenerstrae is considered crucial to detect sound pressure (Fay and Popper 1974; Ketten 1992), because the air/tissue acts as a pressure-to-particle motion transducer. Particle motion alone can be detected by inertial delays in acceleration of higher-density objects versus macular receptors. Taking either case to be valid, hearing may be considered the detection of acoustically generated sound pressure differentials or particle motion or both. Detection of the particle motion component of a sound field has been demonstrated in many marine organisms including cartilaginous and teleost fish that are without specialized adaptations to detect or relay sound pressure reception to the inner ear (de Vries 1950).

Thus we argue that hearing can be validly considered as the detection of broad or isolated elements of sound-generated stimuli and that it may be achieved by a single or multifunctional organ adapted for that 
purpose. The ability to detect sound pressure and/or acoustic particle motion therefore are sufficient qualifiers. Given this premise, many marine organisms capable of detecting acoustically generated particle motion are not, as has often been presumed, unreceptive to sound or its impacts, opening thereby a new area of exploration for the physiology of hearing. We discourage the notion that hearing would be limited to only sound pressure detection; thus many marine organisms, although capable of detecting acoustically generated particle motion, would be considered deaf. It is important to note that according to our definition, a hearing organ may also respond to mechanical disturbances other than sound (such as vibrations, local hydrodynamic waves). We think that this is an important feature, especially in marine particle motion sensors, and that it will be difficult to understand the evolution of hearing without acknowledging this dual function of the sound receiving organs.

\section{Squid Susceptibility to Aquatic Noise}

Any impacts of aquatic noise on cephalopods have yet to be established and are poorly understood. Ambient and anthropogenic ocean noise is substantial at lower frequencies where squid are sensitive (Urick 1983; Packard et al. 1990) suggesting that they will be susceptible to masking or other physiological or behavioral impacts of anthropogenic noise (McCauley et al. 2000). Statocyst or lateral line hair cells could be impacted by sound energy (either long duration or brief, high intensity noise). Such hair cell damage and related temporary hearing loss has been demonstrated in fishes (McCauley et al. 2003) and this has been suggested for squid (which do have a lateral line analogue; Budelmann 1994).

\section{Future Research Directions}

Ideally, detection capabilities would be measured both behaviorally and physiologically. Directed research should identify whether the statocyst acts as the organ of acoustic reception or whether the lateral line analogue may be involved. Finally, the biological relevance of the acoustic stimuli should be addressed. This includes whether squid may hear fish and odontocete predators, the neuroanatomy of auditory structures and if squid are susceptible to the impacts of anthropogenic noise. 
While the field of cephalopod audition has been debated in the past, almost all questions of acoustic detection remain to be addressed. This leaves room for significant and groundbreaking work on the sensory ecology of animals that are often considered keystone species in many ecological webs. Here we have attempted to introduce a preliminary roadmap for such progress and we expect the issue of squid sound detection to be resolved in due time.

\section{References}

Au WWL, Popper AN, Fay RJ (2000) Hearing by whales and dolphins. In. Springer-Verlag, New York

Budelmann BU (1976) Hair cell polarization in the gravity receptor systems of the statocysts of the cephalopods Sepia officinalis and Loligo vulgaris. Brain Res 164:1-5.

Budelmann BU (1992) Hearing in non-arthropod invertebrates. In: Webster DB, Fay RR, Popper AN (ed) The evolutionary biology of hearing. Springer-Verlag, New York, pp 141-155

Budelmann BU (1994) Cephalopod sense organs, nerves and the brain: adaptations for high performance and life style Mar Behav Physiol 25:13 - 33 doi:10.1080/10236249409378905

Clarke MR (1996) Cephalopods as prey. III. Cetaceans. Philos T Roy Soc B 351:10531056.doi:10.1098/rstb.1996.0093

de Vries HL (1950) The mechanics of labyrith otoliths. Acta Oto-Laryngol 38:262-273.

Dijkgraaf S (1963) Verusche uber Schallwahrnehmung bei Tintenfischen. Naturwissenschaften 50:50.doi:10.1007/BF00622830

Fay RJ (1988) Hearing in vertebrates: a psychophysics databook. Hill-Fay, Winnetka, IL

Fay RR Popper AN (1974) Acoustic stimulation of the ear of the goldfish (Carassius auratus). J Exp Biol 61:243-260.

Hu M, Yan HY, Chung W-S, Shiao J-C, Hwang P-P (2009) Acoustical evoked potentials in two cephalopods inferred using the auditory brainstem response (ABR) approach. Comp Biochem Phys A 153:278-283.doi:10.1016/j.cbpa.2009.02.040

Kaifu K, Akamatsu T, Segawa S (2008) Underwater sound detection by cephalopod statocyst. Fish Sci 
74:781-786.doi:10.1111/j.1444-2906.2008.01589.x

Kalmijn AD (1988) Acoustic and hydrodynamic field detection. In: Atema J, Fay RR, Popper AN, Tavolga WN (ed) Sensory biology of aquatic animals. Springer-Verlag, New York, pp 83-131

Ketten DR (1992) The marine mammal ear: specializations for aquatic audition and echolocation. In: Webster DB, Fay RJ, Popper AN (ed) The evolutionary biology of hearing. Springer-Verlag, New York, pp 717-750

Maniwa Y (1976) Attraction of bony fish, squid and crab by sound. In: Schuijf A, Hawkins AD (ed) Sound reception in fish. Elsevier, Amsterdam, pp 271-283

McCauley RD et al. (2000) Marine seismic surveys: Analysis and propagation of air gun signals and effects of air-gun exposure on humpback whales, sea turtles, fishes and squid. Center for Marine Society and Techology and the Australian Petroleum Production and Exploration Association, Curtin

McCauley RD, Fewtrell J, Popper AN (2003) High intensity anthropogenic sound damages fish ears. J Acoust Soc Am 113:638-642.doi:10.1121/1.1527962. 113, 638-642

Moynihan M (1985) Why are cephalopods deaf? Am Nat 125:465-469.doi:10.1086/284353

Nixon M Young JZ (2003) The brains and lives of cephalopods. Oxford University Press, New York

Norris KS Møhl B (1983) Can odontocetes debilitate prey with sound. Am Nat 122:85104.doi:10.1086/284120

Packard A, Karlsen HE, Sand O (1990) Low frequency hearing in cephalopods. J Comp Physiol A 166:501-505.doi:10.1007/BF00192020

Urick RJ (1983) Principles of underwater sound. Mc-Graw-Hill, New York

Webster DB, Fay RR, Popper AN (1992) The evolutionary biology of hearing. In. Springer-Verlag, New York

Wilson M, Hanlon RT, Tyack PL, Madsen PT (2007) Intense ultrasonic clicks from echolocating toothed whales do not elicit anti-predator responses or debilitate the squid Loligo pealeii. Biol Lett-(UK) 3:225-227.doi:10.1098/rsbl.2007.0005

Yost WA (1994) Fundamentals of hearing: An introduction. Academic Press, New York 